\title{
PERSPECTIVE
}

\section{Tobacco: An invisible and immediate threat for COVID 19}

\section{Suneela Garg ${ }^{1}$, Chetana Deshmukh ${ }^{2}$}

${ }^{1}$ Director professor (HAG), National President Elect IAPSM, Country Lead in Addressing Smokeless Tobacco and building Research Capacity in South Asia (ASTRA),York, UK, Maulana Azad Medical College, Delhi; ${ }^{2}$ MBBS,MD,DNB (Community Medicine),Diploma in Applied Epidemiology (NIHFW), Post Doctoral Research fellow, ASTRA (York),UK, Maulana Azad Medical College, Delhi

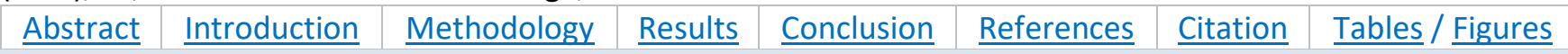

\section{Corresponding Author}

Dr. Chetana Deshmukh, MBBS, MD, DNB (Community Medicine), Diploma in Applied Epidemiology (NIHFW), Post Doctoral Research fellow, ASTRA (York), UK, Maulana Azad Medical College, Delhi E Mail ID: chetana25@gmail.com

\section{Citation}

Garg S, Deshmukh C. Tobacco: An invisible and immediate threat for COVID 19. Indian J Comm Health. 2020;32(2-Special Issue):248-250.

Source of Funding: Nil Conflict of Interest: None declared

Article Cycle

Received: 10/04/2020; Revision: 12/04/2020; Accepted: 18/04/2020; Published: 20/04/2020

This work is licensed under a Creative Commons Attribution 4.0 International License.

\section{Abstract}

One of the major steps to prevent damage due to any pandemic is to focus on risk factors related to the disease. Tobacco consumption is emerging as a major factor out of all for COVID 19. There is hardly any country who has warned the public about this or has made the Tobacco control measures stringent in view of COVID 19. Factors making tobacco consumers more vulnerable to COVID 19 infections are low immunity, damaged cilia in smaller air ways leading to decreased lung capacity and previous history of respiratory illness. Smokers have more expression of ACE2 receptor gene which is also responsible for SARS-COV-2 virus replication in host. More viral load makes smokers potent "carrier". COVID 19 can be transmitted via tobacco consumers by sharing of smoked tobacco and release of vapour droplets. Spitting of smokeless tobacco in public places puts community at risk. Cardiovascular diseases and cancers caused by tobacco consumption act as comorbidities aggravating the symptoms in COVID 19 infection. Scope of FCTC framework can be extended to address prevention and control of COVID 19. Recommendations: tobacco products should be banned immediately to control the spread. MPOWER strategy of FCTC can be utilized in this pandemic to prevent transmission.

\section{Keywords}

Tobacco; COVID-19

When the world is struggling with the major pandemic of COVID 19 having more than 20 lakh cases and nearly 1.3 lakh deaths, India is fighting its best to control the spread of the disease. Currently in India till mid-April there were total 14384 cases and 486 deaths. Isolation of confirmed cases, contact tracing and home quarantine of the contacts along with physical distancing are ongoing measures for prevention and control of COVID 19.

\section{Tobacco consumers and COVID 19 disease}

One of the major steps to prevent damage due to any pandemic is to focus on risk factors related to the disease. Tobacco consumption is emerging as a major factor out of all for COVID 19. In China it has been seen that smokers are 14 times more prone to die by COVID $19(1,2)$. Thus tobacco consumption is possibly associated with adverse prognosis of the respiratory diseases(2). Many studies have highlighted the negative impact of tobacco use on lung health and its causal association with respiratory diseases. In spite of all this, there are very few countries who warned the public about this or has made the Tobacco control and prevention measures stringent in view of COVID 19(3). The 
developed countries are busy declaring economic packages for the people and developing countries are preparing to face the disaster but a thought should also have been given for prevention of risk factors so that damage would be less. (3)

Vulnerability of tobacco consumers to get COVID 19 infection

Use of tobacco in various forms decreases lung capacity. In COPD patient's lungs are in a compromised state. Such predisposing conditions will lead to early and severe symptoms once affected by SARC-CoV- 2 virus. $(4,5,6,7,8)$

Tobacco consumers are more prone for many respiratory tract infections like influenza, SARS and tuberculosis. (6) All these diseases directly or indirectly are associated with low immunity. Thus, tobacco consumers are having low immunity leading to early COVID infections.

Consumption of tobacco causes damage to the cilia of the smaller airways in the lungs. The function of the cilia is to clear the mucus from smaller airways once damaged the mucus is not cleared resulting in clogging of the airways and decrease in lung capacity. (11) This will again help COVID 19 symptoms to increase in severity.

An emerging concept related to ACE2 gene expression which are present on type II pneumocytes of the lungs has become popular in COVID-19 infections. $(8,9,10)$ The study conducted by Cai G. and et al states that ACE2 gene expression is higher in tobacco consumers predominantly in smokers. (12) These ACE2 genes regulate viral replication and hence transmission of the disease. The number of receptors in smokers are more than never smokers so they have more viral load and transmission can occur through them. In another study by Wang et al, an ACE2 connection was noted between smoking and Covid-19. (13)

The virus attaches to the cell surface of ACE2 and gets protection from body immune surveillance. This helps the virus to remain attached to the host for longer duration which makes the host a "carrier". Later on, the virus engulfs ACE2 cells and starts flourishing in host's body. This also helps the virus to mutate. Thus, smokers are at increased risk of severe COVID-19 infection and highlight the importance of smoking cessation in reducing the risk. $(9,10)$

\section{COVID 19 transmission via tobacco users}

\section{Smokeless tobacco products}

India is an abode for considerably high proportion of smokeless tobacco (SLT) users. These SLTs are consumed in various forms like zarda, khaini, paan with areca nut and gutka. Most of these SLTs are initially rubbed on the palms with lime and then the quid is kept in mouth. This mixture is also shared within groups sometimes. This sharing can result in spread of the virus from person to person. The quid is spitted out along with saliva in open spaces in community. This spittoon will be a potent mode of transmission of the virus in the community.

\section{Smoked tobacco products}

Hookah, hosepipes and cigarettes are the various ways of using tobacco in smoked form. These products exhales vapor droplets which will spread the SARS-CoV- 2 in air $(14,15)$. During consumption of these products hands and lips are in contact with each other thereby transmitting the virus from infected hands to mouth and vice versa. This situation is compounded by sharing of smoked tobacco products resulting in transmission of virus.

\section{Existing comorbidity}

Tobacco has direct association with Cardiovascular diseases, Hypertension and Cancer. It is proven fact that people with "existing comorbidity" are more prone for COVID 19 disease. But these existing comorbidities can be one of the above-mentioned diseases making the tobacco consumer more vulnarable for the disease.

\section{FCTC and COVID}

Framework Convention on Tobacco Control (FCTC) is a part of World Health Organization (WHO). The scope of framework can be extended to address prevention and control of COVID 19. It can simultaneously work for implementation of FCTC framework in countries, cessation, of tobacco along with prevention of the pandemic. These will also add-on to the Tobacco free initiative started by WHO all over World.

\section{Recommendation}

- Usage of different forms of smoked tobacco decrease lung capacity and increases lung damage causing severe COVID 19 symptoms. Sharing of tobacco rubbed on hand, cigarettes or shared pipes helps in transmission of disease. These products should be banned immediately to control the spread.

- Sale and spitting of smokeless tobacco products in public places should be banned under COTPA and FCTC in India to prevent the spread of the disease. 
- During Lockdown period, people smoke in their households which will affect the other family members making them vulnerable for severe form of COVID 19 infection. Passive smoking will also have effect on lung capacity and thus should be avoided.

- Decreased use of tobacco will help to prevent the comorbid conditions like Cardiovascular disease and cancer which aggravate the severity of COVID infections were prone for viral infection.

- The MPOWER strategy of FCTC can be very well utilized in this COVID 19 pandemic period to fully implement the FCTC in India. Along with decrease in transmission rate of the disease it will act as good window for tobacco users to move towards quitting.

\section{Authors Contribution}

All authors have contributed equally.

\section{References}

1. Liu W, Tao Z-W, Lei W, Ming-Li Y, Kui L, Ling Z, Shuang W, Yan D, Jing L, Liu H-G, Ming Y, Yi H. Analysis of factors associated with disease outcomes in hospitalized patients with 2019 novel coronavirus disease. Chinese Medical Journal 9000; Publish Ahead of Print.

2. Murin S, Bilello KS. Respiratory tract infections: another reason not to smoke. Cleveland Clinic journal of medicine 2005; 72: 916-920.

3. David Simons OP, Jamie Brown Covid-19: The role of smoking cessation during respiratory virus epidemics. The BMJ Opinion 2020.

4. Wu W, Patel KB, Booth JL, Zhang W, Metcalf JP. Cigarette smoke extract suppresses the RIG-Iinitiated innate immune response to influenza virus in the human lung. American journal of physiology Lung cellular and molecular physiology 2011; 300: L821830.

5. Halim AA AB, Embarak S, Yaseen T, Dabbous S. . Clinical characteristics and outcome of ICU admitted MERS corona virus infected patients. Egyptian Journal of Chest Diseases and Tuberculosis 2016; 65: 81-87.

6. Wong $\mathrm{CM}$, Yang L, Chan KP, Chan WM, Song L, Lai HK, Thach TQ, Ho LM, Chan KH, Lam TH, Peiris JS.
Cigarette smoking as a risk factor for influenzaassociated mortality: evidence from an elderly cohort. Influenza and other respiratory viruses 2013; 7: 531-539.

7. Atto B, Eapen MS, Sharma P, Frey U, Ammit AJ, Markos J, Chia C, Larby J, Haug G, Weber HC, Mabeza G, Tristram S, Myers S, Geraghty DP, Flanagan KL, Hansbro PM, Sohal SS. New therapeutic targets for the prevention of infectious acute exacerbations of COPD: role of epithelial adhesion molecules and inflammatory pathways. Clin Sci (Lond) 2019; 133: 1663-1703.

8. Eapen MS, Sohal SS. Understanding novel mechanisms of microbial pathogenesis in chronic lung disease: implications for new therapeutic targets. Clin Sci (Lond) 2018; 132: 375-379.

9. Brake SJ BK, Lu W, McAlinden KD, Eapen MS, Sohal SS. Smoking Upregulates Angiotensin-Converting Enzyme-2 Receptor: A Potential Adhesion Site for Novel Coronavirus SARS-CoV-2 (Covid-19). Journal of Clinical Medicine 2020; 9: 841.

10. Leung JM, Yang CX, Tam A, Shaipanich T, Hackett TL, Singhera GK, Dorscheid DR, Sin DD. ACE-2 Expression in the Small Airway Epithelia of Smokers and COPD Patients: Implications for COVID-19. medRxiv 2020: 2020.2003.2018.20038455.

11. Petit A, Knabe L, Khelloufi K, Jory M, Gras D, Cabon $Y$, Begg M, Richard S, Massiera G, Chanez P, Vachier I, Bourdin A. Bronchial Epithelial Calcium Metabolism Impairment in Smokers and Chronic Obstructive Pulmonary Disease. Decreased ORAI3 Signaling. Am J Respir Cell Mol Biol. 2019 Oct;61(4):501-511.

12. Cai G. Tobacco-Use Disparity in Gene Expression of ACE2, the Receptor of 2019-nCov. . Preprints 2020, 2020020051 (wwwpreprintsorg) 2020.

13. Wang JL, Q.; Chen, R.; Chen, T.; Li, J. Susceptibility Analysis of COVID-19 in Smokers Based on ACE2. . 2020.

14. Sohal SS, Eapen MS, Naidu VGM, Sharma P. IQOS exposure impairs human airway cell homeostasis: direct comparison with traditional cigarette and ecigarette. ERJ Open Res 2019; 5.

15. Mohammad Ebrahimi Kalan ZBT, Mehdi Fazlzadeh, Kenneth D Ward, Wasim Maziak. Waterpipe Tobacco Smoking: A Potential Conduit of COVID-19. BMJ Tobacco Control 2020 